\title{
Gastric Cancer by AJCC v8 Postneoadjuvant Therapy Stage
}

National Cancer Institute

\section{Source}

National Cancer Institute. Gastric Cancer by A/CC v8 Postneoadjuvant Therapy Stage.

NCI Thesaurus. Code C133641.

A term that refers to the postneoadjuvant therapy staging of gastric cancer according to the American Joint Committee on Cancer, 8th edition. 